\title{
The risk level for individuals to suffering from NCDs based on CERDIK behavior
}

\author{
Suprajitno Suprajitno, Sri Mugianti \\ Department of Nursing, Poltekkes Kemenkes Malang, Malang, Indonesia
}

\begin{tabular}{l}
\hline \hline Article Info \\
\hline Article history: \\
Received Mar 16, 2021 \\
Revised Nov 3, 2021 \\
Accepted Nov 17, 2021 \\
\hline
\end{tabular}

Keywords:

CERDIK behavior

NCDs

Risk of suffering

\begin{abstract}
The use of tobacco, inactivity, alcohol consumption, and an unbalanced diet are factors that cause non-communicable diseases (NCDs) and are considered behavioral factors. Behavior includes knowledge, attitudes, and practice about periodic health checks, getting rid of cigarettes, regular physical activity, a balanced healthy diet, adequate rest, and managing stress (CERDIK) and can be used as a way to measure the risk of an individual suffering from NCDs. The purpose of this study is to describe the individual risk of suffering from NCDs based on the CERDIK behavior. This qualitative study used a cross-sectional design. A sample of 238 individuals who visited fast food restaurants in Blitar were selected by simple random sampling. Data collection used a CERDIK behavior questionnaire consisted of 20 knowledge questions, 29 attitude statements, and 20 practice statements. Data collection was conducted in July - August 2020. The risk of individuals suffering from NCDs in the low category was $8.4 \%, 81.1 \%$ moderate, and $10.5 \%$ high. Practice has an important role in individuals at risk of suffering from NCDs and most individuals are in the moderate category, while a small proportion are in the low and high risk category. It is hoped that health workers routinely and continuously campaign for CERDIK behavior as an effort to prevent NCDs.
\end{abstract}

This is an open access article under the $\underline{C C B Y-S A}$ license.

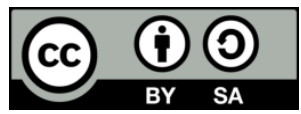

\section{Corresponding Author:}

Suprajitno Suprajitno

Department of Nursing, Poltekkes Kemenkes Malang

Jl. Ijen 77 C Malang, Indonesia

Email: suprajitno_skp@poltekkes-malang.ac.id

\section{INTRODUCTION}

Non-communicable disease (NCDs) is a chronic, long-standing disease or disability that impacts household socioeconomic conditions and is a major cause of death globally [1]. NCDs cause the death of 41 million people per year. Every year, 15 million people who die from NCDs are between the ages of 30 and 69 in low-moderate income countries. Tobacco use, not doing activities, alcohol consumption, and an unbalanced diet are risk factors for the death of people with NCDs [2].

Metabolic factors contribute as a cause of NCDs; changes in metabolism can lead to increased blood pressure, overweight/obesity, hyperglycemia, and hyperlipidemia [2]. Research in China illustrates a link between NCDs and cognitive impairment [3]. Cognitive is a big part of mental activity to gain knowledge [4]. According to Bloom, behavior identifies three domains of knowledge, attitude and practice [5]. Behavior is the result of all kinds of experiences and human interactions with the environment which are manifested in the form of knowledge, attitudes and practice [6].

In Indonesia, avoiding NCDs is not only avoiding tobacco use, not doing activities, and an unhealthy diet, but also having to carry out regular health checks, getting adequate rest, and managing stress. This effort is referred to as behavior (knowledge, attitudes, and practice) of healthy living through periodic 
health checks, getting rid of cigarettes, regular physical activity, a balanced healthy diet, adequate rest, and managing stress (CERDIK) to reduce the risk of suffering from NCDs [7]. Efforts to reduce the risk of suffering from NCDs are directed at maintaining the body's metabolic function, but no one has yet considered CERDIK behavior as a risk factor. Measuring of CERDIK behavior used a questionnaire and to calculate the risk category using (1) [8].

$$
1-\frac{e^{-3.675+0.011 \mathrm{X} 1-0.008 \mathrm{X} 2+0.067 \mathrm{X} 3}}{1+e^{-3.675+0.011 \mathrm{X} 1-0.008 \mathrm{X} 2+0.067 \mathrm{X} 3}}
$$

Where $X_{1}$ is knowledge, $X_{2}$ is attitude, and $X_{3}$ is practice; namely the value of goodness of fit of 0.70 . The risk of suffering from NCDs category are low if it is in the range $0-60.0 \%$, moderate if it is in the range more than $60.0 \%-80.0 \%$, and high if it is more than $80.0 \%$ [8]. The purpose of this study was to calculate the individual risk level of suffering from NCDs based on CERDIK behavior.

\section{METHOD}

This research used quantitative study with a cross sectional design. This research was conducted from June to August 2020. The respondents of this study were 238 individuals who visited fast food and beverage restaurants in the East, West, North, South, and Central regions of Blitar, East Java, Indonesia. Sample size was calculated using $95 \%$ confidence interval, $5 \%$ margin of error with population proportion $50 \%$, and the total of average visits on Friday, Saturday, and Sunday from five fast food restaurants are 600 which results in a minimum sample size of 235. Respondents were selected using simple random sampling. Selected respondents were individuals who visit on Fridays, Saturdays and Sundays between 5 to 9 pm every five people who attend from June to August 2020. The data collected was behavior consisting of knowledge, attitudes, and practice about CERDIK using a questionnaire [8] filled out by respondents. The value of validity test using Pearson correlation and reliability using Cronbach's Alpha for the CERDIK behavioral questionnaire, namely $\mathrm{r}=0.697$ and alpha $=0.604$. The behavioral data obtained were analyzed using Microsoft Excel to calculate and categorize the level of risk. Ethical clearance was given by the Health Research Ethics Committee of the Poltekkes Kemenkes Malang Number 842/KEPK-POLKESMA/2020 on April 6, 2020.

\section{RESULTS AND DISCUSSION}

Cross-tabulation between the likelihood of suffering from hypertension and body mass index with information about CERDIK received by individuals who are at risk of suffering from NCDs is presented in Table 1. General characteristics of individuals and the relationship between the likelihood of suffering from hypertension and body mass index are presented in Table 2 and Table 3. Meanwhile, the behavior scores (knowledge, attitude, and practice) and the individual risk of suffering from NCDs is presented in Table 4 and Table 5.

Table 1. Cross-tabulation between the likelihood of suffering from hypertension and body mass index with information about CERDIK that has been received by individuals who are at risk of suffering from NCDs

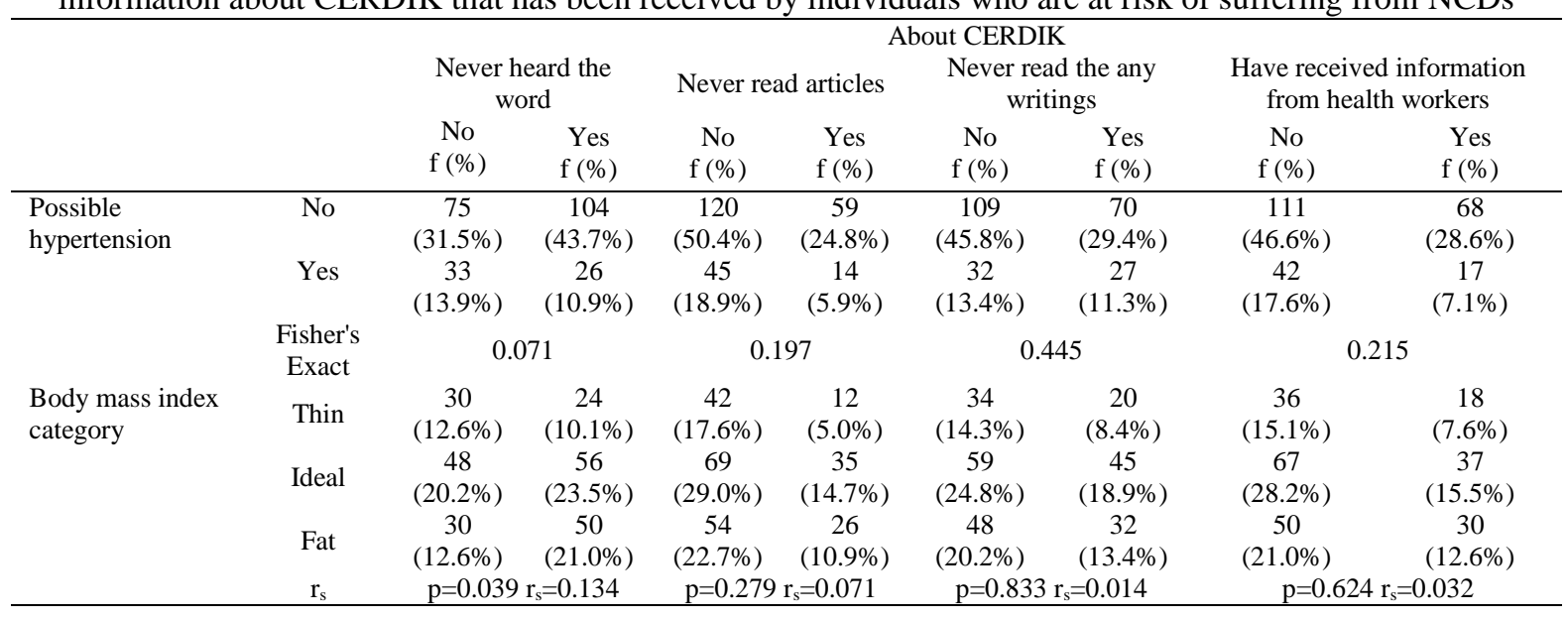

Int J Public Health Sci, Vol. 11, No. 1, March 2022: 179-184 
Table 2. Characteristics of individuals who are at risk of suffering from NCDs

\begin{tabular}{cccccccc}
\hline No. & Characteristics (numeric data) & Min & Max & Average & SD & Skewness & Kurtosis \\
\hline 1 & Age & 15 & 45 & 26.01 & 8.70 & 0.838 & -0.646 \\
2 & Systolic pressure (mmHg) & 90 & 160 & 113.25 & 10.44 & 0.293 & 1.288 \\
3 & Diastolic pressure (mmHg) & 60 & 110 & 79.97 & 8.82 & 0.231 & 0.684 \\
4 & Height (cm) & 105 & 188 & 160.00 & 9.62 & -0.996 & 6.755 \\
5 & Weight (kg) & 39 & 173 & 57.93 & 15.04 & 2.774 & 15.949 \\
6 & Body mass index & 14.53 & 72.95 & 22.62 & 5.80 & 3.807 & 26.524 \\
\hline
\end{tabular}

Table 3. Cross-tabulation between the possibility of suffering from hypertension with body mass index of individuals who are at risk of suffering from NCDs

\begin{tabular}{|c|c|c|c|c|c|c|c|c|c|}
\hline & & \multicolumn{6}{|c|}{ Body Mass Index Category } & \multirow{2}{*}{\multicolumn{2}{|c|}{ Total }} \\
\hline & & \multicolumn{2}{|c|}{$\begin{array}{c}\text { Thin and Very } \\
\text { Thin }\end{array}$} & \multicolumn{2}{|c|}{ Ideal } & \multicolumn{2}{|c|}{ Fat and Obesity } & & \\
\hline \multirow{3}{*}{$\begin{array}{l}\text { Possibility of } \\
\text { suffering from } \\
\text { hypertension }\end{array}$} & & $\mathrm{f}$ & $\%$ & $\mathrm{f}$ & $\%$ & $\mathrm{f}$ & $\%$ & $\mathrm{f}$ & $\%$ \\
\hline & Yes & 13 & 5.5 & 20 & 8.4 & 26 & 10.9 & 59 & 24.8 \\
\hline & Total & 54 & 22.7 & 104 & 43.7 & 80 & 33.6 & 238 & 100.0 \\
\hline
\end{tabular}

Contingency coefficient $=0.133 ; \mathrm{p}=0.177$

Table 4. The value of the behavior of individuals who are at risk of developing NCDs

\begin{tabular}{cccccccc}
\hline No. & Score & Min & Max & Average & SD & Skewness & Kurtosis \\
\hline 1 & Knowledge & 36 & 60 & 51.69 & 5.16 & -0.849 & 0.297 \\
2 & Attitude & 62 & 115 & 94.03 & 9.04 & 0.038 & 0.391 \\
3 & Practice & 22 & 58 & 43.94 & 5.79 & -0.290 & 0.515 \\
4 & Risk & 47.65 & 91.35 & 70.76 & 7.68 & -0.232 & -0.070 \\
\hline
\end{tabular}

Table 5. Individual risk categories for suffering from NCDs

\begin{tabular}{cccc}
\hline No & Category & f & $\%$ \\
\hline \multicolumn{4}{c}{ Risk category } \\
1 & Low & 20 & 8.4 \\
& Moderate & 193 & 81.1 \\
& High & 25 & 10.5 \\
\hline
\end{tabular}

The respondent characteristics presented in Table 2 describe the region of the City and Regency of Blitar. The East, West, North and South regions represent Blitar Regency while the Central region represents Blitar City, because Blitar City is in the middle of Blitar Regency. Thus, the conclusions can be used for generalizations for the Blitar region. NCDs that need to be watched out for an individual aged 15-45 years are hypertension and obesity. Information about CERDIK that has been heard and read through directly or from health workers is not related to the possibility of suffering from hypertension, but information about CERDIK that has been heard has a not strong relationship with obesity (Table 1). CERDIK described individual efforts to avoid risk of suffering from NCDs because NCDs are related to behavioral factors [7], [9]. If CERDIK is carried out by individuals and families regularly, every family in Indonesia can reduce risks and become health innovators in society [9]. The main factors causing NCDs are tobacco use, physical inactivity, alcohol use, and an unhealthy diet [10]. In Indonesia, the prevention of NCDs is known as Healthy Living Behavior through CERDIK Behavior, which the public must do. Community participation in Indonesia to reduce the risk of NCDs is coordinated in the Integrated Guidance organization in every community group, at least in sub-districts or villages [11]. WHO only mentions it as a risk factor, but Indonesia combines risk factors and the efforts that people should make to prevent NCDs [7], [11].

More than half of the individuals who are at risk of suffering from NCDs as shown in Table 1 have heard the word CERDIK, but only about $30 \%$ have read writings, read articles, and received information from health workers about it. CERDIK in Indonesia has been socialized as a community movement for healthy living since 2016 [12]; a balanced healthy diet and physical activity are also agreed as activities to prevent NCDs in seven Asian countries [13]. Socialization activities for healthy living based on Presidential Instruction No.1 of 2017 are the obligations of the Indonesian Ministry of Health and its staff, including health workers. Health workers have three responsibilities, namely a healthy life campaign, education on healthy behavior, and early detection of the risk of suffering from disease [14]. These three obligations mean that health workers must actively provide services to the community, especially to risk groups, and especially those aged 15 years and over. However, the obligations of health workers have never been carried out as 
shown in Table 1. It is proven that $64.3 \%$ stated that they had never received information about CERDIK and only $35.7 \%$ had received information. This situation is in line with the results of research that health workers behave unhealthily and do not have enough experience in providing education about healthy lifestyles [15]. This means that the risk of suffering from NCDs is not only due to individual factors, but health workers also contribute through the inability to carry out their roles.

Individuals are considered hypertensive if they have a systolic pressure of more than $140 \mathrm{mmHg}$ or a diastolic of more than $90 \mathrm{mmHg}$ [16]-[20]; 24.8\% as presented in Table 2 is in line with the indicators of NCDs in the 2015-2019 Rencana Pembangunan Jangka Menengah Nasional/National Mid-Term Development Plan (RPJMN) [11]. The body mass index in the categories of fat and obesity was $33.6 \%$ as shown in Table 1, greater than the 2015-2019 RPJMN indicator, namely 21.8\%. The highest systolic and diastolic blood pressures as shown in Table 2 were 160 and $110 \mathrm{mmHg}$ by comparing the mean and the SD, suggesting that individual blood pressure is pretty much referred to as hypertension. Hypertension as NCDs in adolescents aged 15-19 years is due to consumption of fast food or drinks that contain lots of glucose or carbohydrates. Adolescents are a vulnerable group because they are a transitional age between children and adults. NCDs that occur due to adolescence are obesity, consumption of food insecurity, poor access to healthy food, and exposure to unhealthy environments [21]-[23], also consumption of an unhealthy diet and inadequate physical activity [24].

Individuals who are at risk of suffering from NCDs have a height $160.00+9.62 \mathrm{~cm}$; body weight $57.93+15.04 \mathrm{~kg}$; the lowest body mass index was 14.53 , the highest was 72.95 , and the average was $22.62+5.80$ as presented Table 2 . The body mass of respondents in the fat and obese category was $33.6 \%$ as shown in Table 1, illustrating that the body's metabolism does not take place normally so that more glucose is stored as muscle glycogen. Obesity is caused by the unhealthy behavior of excessive glucose consumption, which is supported by the large number of fast food and drink providers in Blitar, which are crowded with buyers, especially at night. Two of the three common NCDs are hypertension and obesity. Uncontrolled obesity can be a physical hazard and a common cause of death in individuals suffering from NCDs [25]. Thus, health workers at the Community Health Center have a major role in screening individuals aged 15-45 who are at risk of suffering from NCDs and managing them so that they do not become a cause of death [3].

The body mass index in the overweight category was $33.6 \%$ and the possibility of suffering from hypertension was $10.9 \%$ and not hypertension was $22.7 \%$ as shown in Table 3 . Obesity in this situation is due to the large intake of carbohydrates or glucose obtained through the habit of consuming fast food and drinks. Obesity is related to an imbalance between energy intake and expenditure by the body. Genetic, physiological, and behavioral factors as the main causes of obesity [26]. The correlation between body mass index and the possibility of hypertension was analyzed using the Chi square Contingency Coefficient with a value of 0.133 , which means that it has a very low relationship. The results of other studies confirm that body mass index has a significant relationship and influence on hypertension [16], [26]-[30], even increasing age in individuals with obesity has a high risk of suffering from hypertension [27].

According to Bloom, behavior consists of three important activities, namely: i) cognitive, ii) affective, and iii) psychomotor (practice). Cognitive can be measured from knowledge, affective can be measured from attitudes or responses, and psychomotor can be measured by the practice taken [5], [6]. The three activities are consecutive conditions with the logic that individuals can be positive or negative [31], [32] after having enough knowledge. There is much knowledge that is owned, especially information about NCDs, efforts to prevent, direct or indirect sources of information, and existing government programs as material for individuals to act. Knowledge requires mental activity as thinking. After having knowledge, the individual will be positive, that is, supportive, or negative, which is not supportive for taking a practice. The practice referred to in this research is the individual practice of doing CERDIK.

Behavior consisting of knowledge, attitudes, and practices about infectious diseases was measured using a questionnaire [8] which is filled in directly by the individual after receiving information and giving consent to be involved in the research. Knowledge consists of 20 questions with the choice of correct, wrong, and unknowing answers, so that the lowest score is 20 and the highest is 60. Attitudes consist of 29 statements with choices of strongly agree, agree, disagree, and strongly disagree, so the lowest score is 29 and the highest is 116 . The practice consists of 20 statements with choices often/always, sometimes, and never, so the lowest score is 20 and the highest is 60. The mean and standard deviation of knowledge, attitudes, and practice of individuals who are at risk of suffering from NCDs is $51.69 \pm 5.16$; $94.03 \pm 9.04$; and 43.94 \pm 5.79 , respectively as shown in Table 4 .

Knowledge can be obtained in several ways; i) through direct personal experience or various secondary elements which provide various information which often contradicts one another; ii) seek and receive explanations from certain persons who have control or who are deemed authorized; iii) deductive reasoning; and iv) the search for knowledge that begins with observing specific things or concrete (inductive) facts. Attitude is related to personality and motivation, which is always prepared, studied, and regulated 
through experience [32]. Practice is the activity of a person carrying out activities to achieve certain goals which are influenced by objective attitudes and norms. Practices are formed by the experience of individual interactions with the environment, especially regarding knowledge and attitudes toward an object. De Werdt's research says that there is a strong influence of the level of knowledge on practice [6]. The behavior theory that makes individuals take practice in an effort to prevent NCDs is known as the AIETA model. Namely; i) Awareness, the individual has previously known the stimulus, ii) Interest, there is a feeling of being attracted to the stimulus (object) so that the attitude begins to appear, iii) Evaluation, considering whether or not the stimulus is within him, this condition means that the attitude is better, iv) Trial, the individual begins to do something as desired by the stimulus, and (v) Adoption, the individual behaves in accordance with the knowledge and attitude [4].

Individuals who have received information from health workers and read articles about CERDIK have knowledge of efforts to prevent NCDs. Furthermore, individuals respond and behave toward CERDIK, finally taking practice so as not to suffer from NCDs. The results showed that the average value and standard deviation of CERDIK's behavior includes knowledge, attitudes, and practice, namely $70.76 \pm 7.68$ as shown in Table 4. The risk of individuals suffering from NCDs in the low category was $8.4 \%, 81.1 \%$ moderate, and $10.5 \%$ high as shown in Table 5. What is meant in research into the risk of suffering from NCDs is the large risk of an individual suffering from hypertension and obesity in a percentage as measured by intelligent behavior (knowledge, attitudes, and practice). Factors causing NCDs determined by WHO are tobacco use, physical inactivity, drinking alcoholic beverages, and unhealthy diet [2] and is no different from the CERDIK behaviour [7], but even more complete with the behavior of regular health checks, adequate rest, and managing stress. That is, the measurement of behavior (knowledge, attitudes, and practice) also describes efforts to prevent NCDs by individuals.

Individuals who have a low risk, statistically have sufficient knowledge and attitude value, but make routine practice efforts at all times. Meanwhile, individuals who have a high risk have a low practice value. This condition is in line with the results of the research that the act of CERDIK is the most important factor in behavior for measuring the risk of NCDs [8]. Prevention efforts so that death from NCDs [2] can be controlled require the efforts of health workers on a regular basis and continuously socializing CERDIK behavior in every health service provided at the Community Health Center.

\section{CONCLUSION}

Practice has an important role in individuals at risk of suffering from NCDs and most individuals are in the moderate category, while a small proportion are in the low and high risk category. It is suggested that health workers routinely and continuously campaign for CERDIK behavior as an effort to prevent NCDs.

\section{ACKNOWLEDGEMENTS}

The author would like to thank the Director of Poltekkes Kemenkes Malang and the respondents.

\section{REFERENCES}

[1] Ministry of Health of RI, "National Health Indicators Survey Report of 2016," Jakarta, 2016. https://labmandat.litbang.kemkes.go.id/riset-badan-litbangkes/menu-riskesnas/menu-rikus/422-sirk-2016 (accessed 10 March 2020)

[2] WHO, "Noncommunicable diseases," 2018. https://www.who.int/news-room/fact-sheets/detail/noncommunicable-diseases (accessed 26 November 2020).

[3] V. S. Yiengprugsawan and C. J. Browning, "NCDs and cognitive impairment: pathways and shared behavioral risk factors among older chinese," Frontiers in Public Health vol. 7, p. 296, Oct. 2019, doi: 10.3389/fpubh.2019.00296.

[4] E. M. Rogers, "Diffusion of Innovations", Fith. New York: Free Press, 2003. https://bloch.umkc.edu/awareness-curve/ (accessed 19 November 2020)

[5] University of Leicester, "Benajamin Bloom." 2017. https://www.eidesign.net/understanding-basics-blooms-taxonomyapplication-elearning/ (accessed 30 November 2020).

[6] S. Notoatmodjo, Health Education and Behavior. Jakarta: Rineka Cipta, 2012.

[7] Ministry of Health of RI, "Public Health News No. 1/2017," Jakarta, p. 27, 2017. https://promkes.kemkes.go.id/?p=7871 (accessed 12 March 2020).

[8] Suprajitno and S. Mugianti, "CERDIK behavior as a risk factor for individuals with NCDs," Syst. Rev. Pharm., vol. 11, no. 10, pp. 350-360, 2020.

[9] E. Warganegara and N. N. Nur, "Behavioral risk factors for NCDs," Majority, vol. 5, no. 2, pp. 88-94, Apr. 2016.

[10] WHO, "Noncommunicable diseases," 2020. https://www.who.int/health-topics/noncommunicable-diseases\#tab=tab_1 (accessed 12 June 2020).

[11] Ministry of Health of RI, "Handbook of Non-Communicable Disease Management. Jakarta: Directorate of Prevention and Control of NCDs." 2019. Available: http://p2ptm.kemkes.go.id/dokumen-ptm/buku-pedoman-manajemen-ptm (accessed 12 March 2020).

[12] Ministry of Health of RI, "General Guidelines for the Healthy Indonesia Program with a Family Approach." Jakarta: General Secretariat, 2016. https://dinkes.jatimprov.go.id/userfile/dokumen/Buku_Pedoman_PIS_PK.pdf (accessed 10 March) 2020

[13] T. Tuangratananon et al., "Implementation of national action plans on noncommunicable diseases, Bhutan, Cambodia, Indonesia, 
Philippines, Sri Lanka, Thailand and Vietnam,” Bull. World Health Organ., vol. 97, no. 2, pp. 129-141, Feb. 2019, doi: 10.2471\%2FBLT.18.220483.

[14] Cabinet Secretariat of RI, "Presidential instruction of the Republic of Indonesia Number 1 of 2017 about Healthy Living Community Movement.” Jakarta 2017. https://peraturan.bpk.go.id/Home/Details/77301/inpres-no-1-tahun-2017 (accessed 10 March 2020).

[15] A. A. T. Tejoyuwono, "Health lecturers and students views' about healthcare workers' as healthy lifestye role models: a qualitative study," IJNP Indonesian J. Nurs. Pract., vol. 4, no. 1, pp. 28-36, Jul. 2020, doi: 10.18196/ijnp.41105.

[16] S. Ahmed, S. Pervin, T. Biswas, M. A. H. Chowdhury, M. A. Hasnat, and M. M. R. Shuvra, "Undiagnosed isolated systolic and diastolic hypertension subtypes and their correlates in Bangladesh: a nationwide survey," Osong Public Heal. Res. Perspect., vol. 10, no. 1, pp. 12?19, Feb. 2019, doi: 10.1186/s12889-019-7101-x.

[17] A. M. Iqbal and S. F. Jamal, Essential Hypertension - StatPearls - NCBI Bookshelf. StatPearls Publishing, Treasure Island (FL), 2021.

[18] WHO, "Hypertension,” 2019. https://www.who.int/news-room/fact-sheets/detail/hypertension (accessed 12 November 2020

[19] R. Bunag, "Essential hypertension," xPharm: The Comprehensive Pharmacology Reference, pp. 1-6, 2007, doi: 10.1016/B978008055232-3.60057-1.

[20] Ministry of Health of RI, "Classification of Hypertension," Directorate general of disease prevention and control." 2018. http://p2ptm.kemkes.go.id/infographic/klasifikasi-hipertensi (accessed 12 November 2020).

[21] R. Kelishadi and M. Heidari-Beni, "Prevention and control of childhood obesity: the backbone in prevention of non communicable disease," Advances in Experimental Medicine and Biology, vol. 1121, pp. 61-66, 2019, doi: 10.1007/978-3-03010616-4_7.

[22] L. L. Hardy, S. Mihrshahi, W. Bellew, A. Bauman, and D. Ding, "Children's adherence to health behavior recommendations associated with reducing risk of non-communicable disease," Prev. Med. Reports, vol. 8, pp. 279-285, Dec. 2017, doi: 10.1016/j.pmedr.2017.10.006.

[23] B. Mikkelsen et al., "Life course approach to prevention and control of NCDs," BMJ, vol. 364, pp. 20-23, Jan. 2019, doi: $10.1136 / \mathrm{bmj} .1257$

[24] A. T. Olawuyi and I. A. Adeoye, "The prevalence and associated factors of noncommunicable disease risk factors among civil servants in Ibadan, Nigeria," PLoS One, vol. 13, no. 9, Sep. 2018, doi: 10.1371/journal.pone.0203587.

[25] S. Licher et al., "Lifetime risk and multimorbidity of NCDs and disease-free life expectancy in the general population: A population-based cohort study," PLoS Med., vol. 16, no. 2, Feb. 2019, doi: 10.1371/journal.pmed.1002741.

[26] C. Wilborn et al., "Obesity: prevalence, theories, medical consequences, management, and research directions," J. Int. Soc. Sports Nutr., vol. 2, no. 2, pp. 4-31, Dec. 2005, doi: 10.1186/1550-2783-2-2-4.

[27] N. K. Mungreiphy, S. Kapoor, and R. Sinha, "Association between BMI, blood pressure, and age: study among Tangkhul Naga Tribal Males of Northeast India,?” J. Anthropol., vol. 2011, pp. 1-6, 2011, doi: 10.1155/2011/748147.

[28] F. Vuvor, "Correlation of body mass index and blood pressure of adults of 30-50 years of age in Ghana," J. Heal. Res. Rev., vol. 4, no. 3, pp. 115-121, 2017, doi: 10.4103/jhrr.jhrr_93_16.

[29] S. Dua, M. Bhuker, P. Sharma, M. Dhall, and S. Kapoor, "Body mass index relates to blood pressure among adults," N. Am. J. Med. Sci., vol. 6, no. 2, pp. 89-95, Feb. 2014, doi: 10.4103\%2F1947-2714.127751.

[30] F. Landi et al., "Body mass index is strongly associated with hypertension: results from the longevity check-up 7+ study," Nutrients, vol. 10, no. 12, Dec. 2018, doi: 10.3390\%2Fnu10121976.

[31] S. Azwar, Human Attitude: Theory and Measuring. Yogyakarta: Pustaka Pelajar, 2014.

[32] J. L. Gibson, J. M. Ivancevich, J. H. Donnelly, and R. Konopaske, Organizations: behavior, structure, processes, 14th Ed. New York: McGraw-Hill, 2011.

\section{BIOGRAPHIES OF AUTHORS}

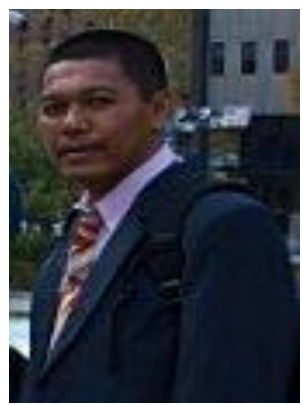

Suprajitno (iD) SC P is a Register Nurse as a Lecturer at Poltekkes Kemenkes Malang. Expertise in Community and Family Nursing, also has expertise in Biostatistics. Completed education is a Bachelor of Nursing at the University of Indonesia, and a Master's degree in Biostatistics and a Doctorate in Health Sciences at the University of Airlangga. His research focuses on community nursing and public health in particular prevention and noncommunicable diseases. He can be contacted at e-mail suprajitno_skp@poltekkesmalang.ac.id.

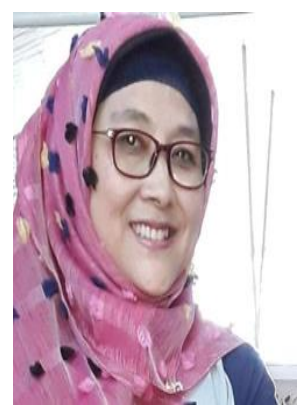

Sri Mugianti (D) 81 SC P is a Register Nurse as a Lecturer at Poltekkes Kemenkes Malang, also active in Pramuka activities. Expertise in Nursing Management and Disaster Nursing Management. Completed education is a Bachelor of Nursing at the University of Airlangga, and a Master's degree in Nursing at University of Indonesia, and a Doctorate in Social Sciences at the University of Merdeka of Malang. Her research focuses on nursing management and disaster nursing management especially in Mount Kelud, Blitar region. She can be contacted at e-mail sri.mugianti@gmail.com. 